\title{
Association of factor XIII Val34Leu polymorphism and coronary artery disease: A meta-analysis
}

\author{
Jae Hyun Jung ${ }^{1,2}$, Gwan Gyu Song ${ }^{1,2}$, Jae-Hoon Kim ${ }^{1,2}$, Young Ho Seo ${ }^{1,3}$, Sung Jae Choi ${ }^{1,3}$ \\ ${ }^{1}$ Korea University College of Medicine, Seoul, Korea \\ ${ }^{2}$ Department of Internal Medicine, Division of Rheumatology, \\ Korea University Guro Hospital, Seoul, Korea \\ ${ }^{3}$ Department of Internal Medicine, Division of Rheumatology, \\ Korea University Ansan Hospital, Ansan-si, Gyeonggi-do, Korea
}

\begin{abstract}
Background: Factor XIII plays an important role in the stabilization of the linkage between fibrins and in the pathophysiology of coronary artery disease (CAD). The association between factor XIII Val34Leu polymorphism and $C A D$ risk remains controversial.

Methods: We conducted a meta-analysis of 36 studies involving 26,940 cases and 34,694 controls. Subgroup analyses were performed with division of data into disease (myocardial infarction [MI], CAD without MI), age, and sex.

Results: Factor XIII Val34Leu polymorphism was significantly associated with ove all CAD risk (odds ratio $[O R]=1.09,95 \%$ confidence interval $[C I]=1.03-1.06, p=0.004)$ and $M I$ risk $(O R=1.15$, $95 \%$ CI 1.07-1.25, $p=0.0003)$, but not with CAD without MI risk (OR $=1.00,95 \%$ CI 0.87-1.15, $p=0.96$ ). In the subgroup analysis by age and sex, there was no association between Val34Leu polymorphism and $C A D$.

Conclusions: This meta-analysis found that factor XIII Val34Leu polymorphism was associated with $C A D$ risk, especially $M I$, but not with CAD without MI. In addition, age and sex did not affect the relationship between factor XIII Val34Leu polymorphism and CAD risk. (Cardiol J 2017; 24, 1: 74-84)

Key words: factor XIII A Val34Leu, coagulation, coronary artery disease, myocardial infarction, meta-analysis
\end{abstract}

\section{Introduction}

Coronary artery disease (CAD) is the leading cause of death worldwide. Approximately 85.6 million American adults suffer from coronary vascular disease and around $30 \%$ of all deaths in 2013 were caused by CAD [1]. Although CAD mortality has decreased in recent years, it still remains high. CAD is a multifactorial disease with a complex pathophysiology generated by the combined effects of genes and the environment. Improvement of environmental factors can reduce the rate of
CAD prevalence and mortality, but genetic factors remain a problem in CAD. A number of genetic risk factors have been found to predispose individuals to $\mathrm{CAD}$, and the coagulation factor XIII gene, factor XIII, has been extensively studied.

Factor XIII plays an important role in the stabilization of linkages between fibrins and in the pathophysiology of CAD [2, 3]. Factor XIII consists of two types of subunits $\left(\mathrm{A}_{2}\right.$ and $\left.\mathrm{B}_{2}\right)$. Factor XIII-A consists of two active A subunits, and factor XIII-B consists of inhibitory/carrier B subunits. Factor XIII-A, which shows transglutaminase activity,

\footnotetext{
Address for correspondence: Prof. Sung Jae Choi, Division of Rheumatology, Department of Internal Medicine, Korea University Ansan Hospital, 123, Jeokgeum-ro, Danwon-gu, Ansan-si, Gyeonggi-do, 15355, Korea, tel: +82-31-412-6760, fax: +82-31-412-5984, e-mail: csjmd888@korea.ac.kr 
strengthens fibrin polymers and protects them from degradation by the fibrinolytic machinery [4]. Many studies have investigated the association between factor XIII-A gene polymorphisms and susceptibility to CAD, especially myocardial infarction (MI). Most studies have focused on one single-nucleotide polymorphism (SNP), which was Val34Leu.

In 2014, two meta-analytical studies were published on the association between factor XIII Val34Leu polymorphism and MI. Chen et al. [5] analyzed 29 studies and showed that factor XIII Val34Leu polymorphism may be associated with the risk of MI, and Wang et al. [6] analyzed 12 studies and showed the same result. However, the association between overall CAD and factor XIII Val34Leu polymorphism has not been analyzed since 2007 [7]. The results of a meta-analysis by Voko et al. [7] suggest that factor XIII Val34Leu polymorphism also affects susceptibility to CAD. In the present study, we performed a meta-analysis of all eligible studies to assess the relationship of factor XIII Val34Leu polymorphism with risk of CAD.

\section{Methods}

\section{Identification of eligible studies and data extraction}

A literature search was performed for studies examining the association between factor XIII Val34Leu and CAD. The PUBMED and EMBASE citation databases were used to identify available articles in which the factor XIII Val34Leu polymorphism was analyzed in patients with CAD (up to May 2016). The search terms used were as follows: coronary artery disease, myocardial infarction, angina, ischemic heart disease, factor XIII or F13A1, polymorphism, and mutation or variant. References in identified studies were also investigated to identify additional studies not indexed by PUBMED or EMBASE. Studies were included in this meta-analysis if 1 ) they were case-control studies that determined the distribution of factor XIII Val24Leu polymorphism; 2) they contained original data; and 3) they provided sufficient data to calculate odd ratios (ORs). No restrictions were set on race, language, ethnicity, or geographic area. We excluded the following: 1) studies with overlapping data; 2) studies in which the number of null and wild-type genotypes or alleles could not be ascertained; and 3) studies with only an abstract. We extracted author, year of publication, ethnicity of the study population, demographics, number of cases and controls, and allele frequency of factor XIII Val34Leu polymorphism.

\section{Statistical analysis}

Prior to pooling the studies for meta-analysis, the Hardy-Weinberg equilibrium (HWE) was assessed in the control groups of each study. Chisquare test was used to determine whether the observed frequency of genotypes in the control population conformed to HWE expectations. A two-sided p value $>0.05$ was considered consistent with the HWE. Statistical analyses were performed using Review Manager 5.3 (The Nordic Cochrane Center, The Cochrane Collaboration, 2014). We performed meta-analyses using 1) allelic contrast, 2) homozygote contrast, and 3) recessive and 4) dominant models. The strength of the association between factor XIII Val34Leu polymorphism and CAD risk was measured by OR and $95 \%$ confidence interval $(\mathrm{CI})$. Heterogeneity statistics $\left(\mathrm{I}^{2}\right)$, overall effect ( $Z$ score), and $\mathrm{p}$ value were calculated. The effect of heterogeneity was quantified using $\mathrm{I}^{2}$, which ranges from $0 \%$ to $100 \%$ and represents the proportion of between-study variability attributable to heterogeneity rather than chance [8]. The $\mathrm{I}^{2}$ values of $25 \%, 50 \%$, and $75 \%$ were nominally considered low, moderate, and high estimates, respectively. With an $\mathrm{I}^{2}$ value $<25 \%$ or $\mathrm{p}$ value of heterogeneity $>0.10$, a fixed effect model was selected for Mantel-Haenszel statistics. Otherwise, a random-effect model was used [9]. A funnel plot test was used to assess publication bias and was set at $\mathrm{p}<0.10$. To evaluate disease-, age-, and sex-specific effects, subgroup analyses were performed based on disease status, age, and sex. Early-onset MI was defined as a cardiac event occurring before the age of 45 years.

\section{Results}

\section{Studies included in the meta-analysis}

Electronic and manual searches identified 156 applicable studies, and 42 were selected for a full-text review based on the title and abstract details. Three studies were excluded due to duplicate data, and other three studies were excluded because they were meta-analytical studies between factor XIII Val24Leu polymorphism and CAD or MI. A total of 36 studies met the inclusion criteria, and separate comparisons were considered in the present meta-analysis, which included 26,940 cases and 34,694 controls [2, 10-44] (Table 1). There were 25 studies performed in European populations, 3 studies in Asian populations, 6 studies in North American populations, 1 study in a South American population, and 1 study in an African population. The present meta-analysis included overall CAD including 


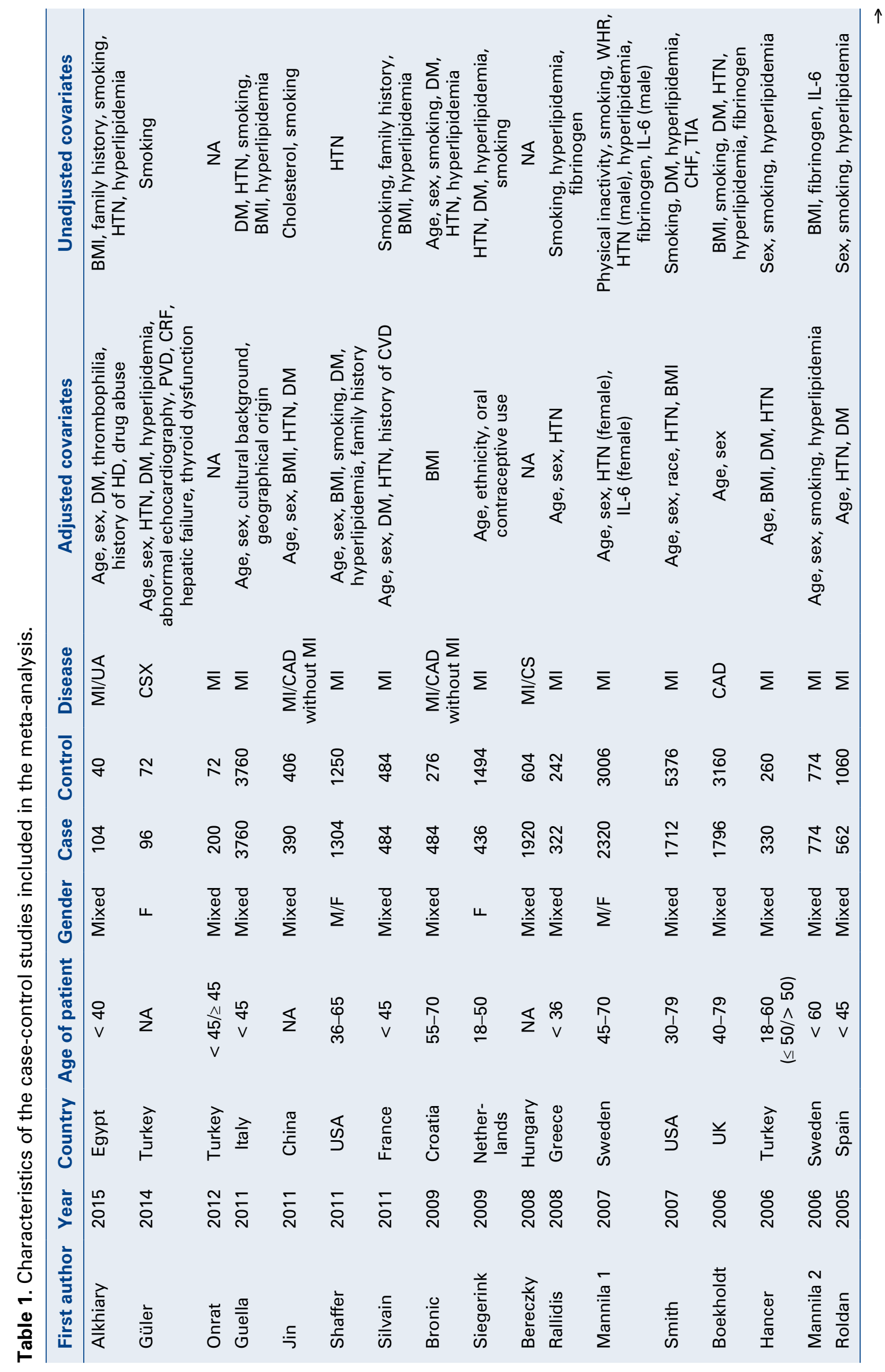




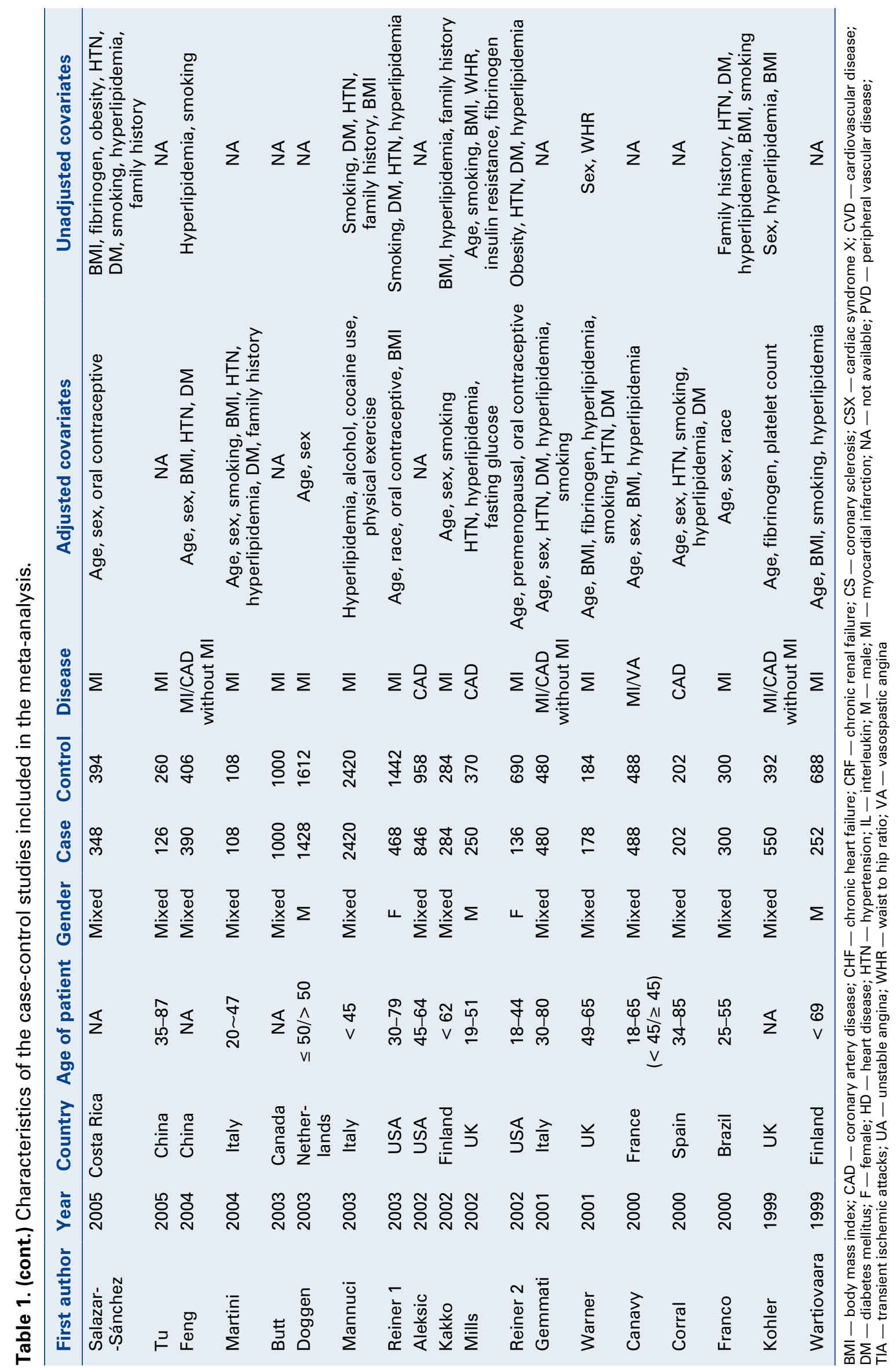


Table 2. Meta-analysis of association between the factor XIII Val34Leu polymorphism and coronary artery disease.

\begin{tabular}{|c|c|c|c|c|c|c|c|c|c|}
\hline \multirow[t]{2}{*}{ Population } & \multirow{2}{*}{$\begin{array}{l}\text { Number } \\
\text { of studies }\end{array}$} & \multirow[t]{2}{*}{ Case } & \multirow[t]{2}{*}{ Control } & \multicolumn{3}{|c|}{ Test of association } & \multicolumn{3}{|c|}{ Test of heterogeneity } \\
\hline & & & & OR & $95 \% \mathrm{Cl}$ & $\mathbf{P}$ & Model & $\mathbf{P}$ & $\left.\right|^{2}(\%)$ \\
\hline Overall & 36 & 26940 & 34694 & 1.09 & $1.03-1.16$ & 0.004 & $\mathrm{R}$ & 0.003 & 44 \\
\hline MI & 31 & 21168 & 29932 & 1.15 & $1.07-1.25$ & 0.0003 & $\mathrm{R}$ & 0.0001 & 55 \\
\hline Without MI & 9 & 2678 & 3164 & 1.00 & $0.05-0.96$ & 0.96 & $\mathrm{~F}$ & 0.28 & 18 \\
\hline Under 45 & 9 & 8098 & 9256 & 1.03 & $1.96-1.11$ & 0.4 & $\mathrm{~F}$ & 0.1 & 41 \\
\hline Over 45 & 7 & 4260 & 5020 & 0.90 & $0.75-1.08$ & 0.25 & $\mathrm{R}$ & 0.08 & 47 \\
\hline Male & 5 & 4268 & 5350 & 1.08 & $0.94-1.25$ & 0.27 & $\mathrm{R}$ & 0.09 & 50 \\
\hline Female & 6 & 2114 & 4954 & 1.09 & $0.97-1.24$ & 0.15 & $\mathrm{~F}$ & 0.13 & 41 \\
\hline
\end{tabular}

$\mathrm{Cl}$ - confidence interval; $\mathrm{F}$ - fixed effects model; $\mathrm{MI}$ - myocardial infarction; OR - odds ratio; $\mathrm{R}$ - random effects model

MI, unstable angina, coronary sclerosis, cardiac syndrome $\mathrm{X}$, vasospastic angina, etc. A total of 9 studies were performed with patients younger than 45 years; among these, 2 studies also contained patients older than 45 years. Including these 2 studies, a total of 8 studies were performed in patients older than 45 years. Three studies included only male patients, 4 studies only females, and all other included both sexes. Two study analyses were performed separately based on sex.

\section{Meta-analysis of the association between factor XIII Val34Leu polymorphism and coronary artery disease}

A summary of the meta-analysis findings concerning associations between factor XIII Val34Leu polymorphism and CAD is provided in Table 2. The meta-analysis of factor XIII Val34Leu polymorphism showed a significant association between $\mathrm{CAD}$ and the Val allele $(\mathrm{OR}=1.09,95 \% \mathrm{CI}$ $1.03-1.06, p=0.004$; Fig. 1). A subgroup analysis by disease type (with MI or without MI) showed a significant association between $\mathrm{MI}$ and the Val allele $(\mathrm{OR}=1.15,95 \%$ CI 1.07-1.25, $\mathrm{p}=0.0003$; Fig. 2). However, no association was found between $\mathrm{CAD}$ without $\mathrm{MI}$ and the Val allele $(\mathrm{OR}=1.00,95 \%$ CI $0.87-1.15, \mathrm{p}=0.96)$. In the subgroup analysis by age, no association was found in either the younger population $(\mathrm{OR}=1.03,95 \% \mathrm{CI} 0.96-1.11, \mathrm{p}=0.4)$ or older population $(\mathrm{OR}=0.90,95 \% \mathrm{CI} 0.75-1.08$, $\mathrm{p}=0.25)$. In the subgroup analysis by sex, no association was found in males $(\mathrm{OR}=1.08,95 \% \mathrm{CI}$ $0.94-1.25, \mathrm{p}=0.27)$ or females $(\mathrm{OR}=1.09,95 \%$ CI $0.97-1.24, \mathrm{p}=0.15)$.

We compared the Val/Val genotype and Val/Leu $+\mathrm{Leu} /$ Leu genotype in the overall CAD population and subgroups. There was a significant association between $\mathrm{CAD}$ and the $\mathrm{Val} / \mathrm{Val}$ genotype $(\mathrm{OR}=1.11$, 95\% CI 1.03-1.19, $p=0.006$; Fig. 3). In the subgroup analysis, there was a significant association between $\mathrm{MI}$ and the $\mathrm{Val} / \mathrm{Val}$ genotype in the $\mathrm{CAD}$ with $\mathrm{MI}$ group $(\mathrm{OR}=1.18,95 \%$ CI 1.08-1.30, $\mathrm{p}=0.0003$; Fig. 4). However, in the other subgroup analyses, there were no associations between disease and the $\mathrm{Val} / \mathrm{Val}$ genotype. We also compared the $\mathrm{Val} / \mathrm{Val}$ genotype and the Leu/Leu genotype in the overall CAD population and subgroups. Comparison of the Val/Val vs. LeuLeu genotypes of overall CAD $(\mathrm{OR}=1.19,95 \%$ CI $1.03-1.38$, $\mathrm{p}=0.02)$ and $\mathrm{MI}(\mathrm{OR}=1.27,95 \%$ CI $1.06-1.52$, $\mathrm{p}=0.009$ ) also showed a significant association, however other subgroups showed no associations.

\section{Heterogeneity and publication bias}

Some heterogeneity was found in the metaanalyses of the factor XIII Val34Leu polymorphisms (Table 2). For MI risk, there was significant heterogeneity in the Val allele $\left(\mathrm{I}^{2}=55 \%, \mathrm{p}=0.0001\right.$; Table 3), and the Val/Val vs. Val/Leu + Leu/Leu genotype model $\left(\mathrm{I}^{2}=53 \%, \mathrm{p}=0.0003\right.$; Table 3$)$. There was also significant heterogeneity in the Val/ /Val vs. Val/Leu + Leu/Leu genotype model in the group of subjects older than 45 years $\left(\mathrm{I}^{2}=67 \%\right.$, $\mathrm{p}=0.006)$ and in the Val allele in males $\left(\mathrm{I}^{2}=50 \%\right.$, $\mathrm{p}=0.09$ ). All studies included in this meta-analysis satisfied the HWE. Publication bias was examined by a funnel plot (Fig. 5). The shape of the funnel plot was symmetrical, with 18 studies on the left side and 18 studies on the right side.

\section{Discussion}

In the current meta-analysis, we investigated the association between factor XIII Val34Leu 


\begin{tabular}{|c|c|c|c|c|c|c|c|c|c|c|c|}
\hline \multirow{3}{*}{$\begin{array}{l}\text { Studror Suberoue } \\
\text { Alkhiary }\end{array}$} & \multicolumn{2}{|c|}{ Coronary artery disease } & \multicolumn{2}{|c|}{ Control } & \multirow{2}{*}{\multicolumn{3}{|c|}{ Odds Ratio }} & \multirow{2}{*}{\multicolumn{3}{|c|}{$\begin{array}{c}\text { Odds Ratio } \\
\text { M.H. Random, } 95 \mathrm{~K} \mathrm{Cl}\end{array}$}} & \\
\hline & Events & Total & Events & Total & Weight & & Year & & & & \\
\hline & 97 & 104 & 34 & 40 & $0.3 \%$ & $2.45[0.77 .7 .79]$ & 2015 & & & & \\
\hline Güler & 73 & 96 & 64 & 72 & $0.5 \%$ & $0.40[0.17,0.95]$ & 2014 & & & & \\
\hline Onrat & 150 & 200 & 61 & 72 & $0.7 \%$ & $0.54\{0.26,1.11]$ & 2012 & & & & \\
\hline Guella & 3008 & 3760 & 3008 & 3760 & $6.4 \%$ & $1.00[0.89,1.12\rceil$ & 2011 & & & - & \\
\hline Jin & 381 & 390 & 396 & 406 & $0.4 \%$ & $1.07[0.43,2.66]$ & 2011 & & & & \\
\hline Silvain & 369 & 484 & 355 & 484 & $2.9 \%$ & $1.17[0.87,1.56]$ & 2011 & & & & \\
\hline Shaffer & 983 & 1304 & 917 & 1250 & $4.8 \%$ & $1.11[0.93,1.33]$ & 2011 & & & & \\
\hline Bronic & 369 & 484 & 206 & 276 & $2.3 \%$ & $1.09[0.77,1.54]$ & 2009 & & & & \\
\hline Siegerink & 328 & 436 & 1121 & 1494 & $3.5 \%$ & $1.01[0.79,1.29\}$ & 2009 & & & & \\
\hline Bereczky & 1438 & 1920 & 448 & 604 & $4.2 \%$ & $1.04|0.84,1.28|$ & 2008 & & & & \\
\hline Rallidis & 265 & 322 & 178 & 242 & $1.8 \%$ & $1.67[1.12,2.50]$ & 2008 & & & 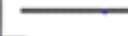 & \\
\hline Mannila (1) & 1725 & 2320 & 2235 & 3006 & $6.1 \%$ & $1.00[0.88,1.13\}$ & 2007 & & & - & \\
\hline Smith & 1258 & 1712 & 3769 & 5376 & $6.2 \%$ & $1.18\{1.05,1.33\}$ & 2007 & & & $\rightarrow$ & \\
\hline Mannila (2) & 575 & 774 & 574 & 774 & $3.8 \%$ & $1.01[0.80,1.26]$ & 2006 & & - & & \\
\hline Hancer & 275 & 330 & 210 & 260 & $1.7 \%$ & $1.19|0.78,1.82|$ & 2006 & & & & \\
\hline Boekholdt & 1294 & 1796 & 2334 & 3160 & $6.0 \%$ & $0.91[0.80,1.04]$ & 2006 & & - & & \\
\hline Tu & 126 & 126 & 258 & 260 & $0.0 \%$ & $2.45|0.12,51.35|$ & 2005 & & & & \\
\hline Roldan & 446 & 562 & 865 & 1060 & $3.4 \%$ & $0.87[0.67 .1 .12 \mid$ & 2005 & & & - & \\
\hline Salazar-Sánchez & 270 & 348 & 274 & 394 & $2.4 \%$ & $1.52\{1.09,2.11]$ & 2005 & & & - & \\
\hline Feng & 381 & 390 & 396 & 406 & $0.4 \%$ & $1.07[0.43,2.66]$ & 2004 & & & & \\
\hline Martini & 91 & 108 & 91 & 108 & $0.6 \%$ & $1.00[0.48,2.08\}$ & 2004 & & & & \\
\hline Reiner (1) & 372 & 468 & 1072 & 1442 & $3.4 \%$ & $1.34[1.04,1.72]$ & 2003 & & & & \\
\hline Mannuci & 1933 & 2420 & 1941 & 2420 & $5.7 \%$ & $0.98[0.85,1.13\}$ & 2003 & & - & - & \\
\hline Doggen & 829 & 1120 & 964 & 1292 & $4.7 \%$ & $0.97[0.81,1.16 \mid$ & 2003 & & & - & \\
\hline Buta & 723 & 1000 & 729 & 1000 & $4.4 \%$ & $0.97[0.80,1.18$ & 2003 & & & - & \\
\hline Aveksic & 661 & 846 & 754 & 958 & $3.9 \%$ & $0.97[0.77,1.21]$ & 2002 & & & & \\
\hline Reiner (2) & 106 & 136 & 512 & 690 & $1.6 \%$ & $1.23[0.79,1.91]$ & 2002 & & & & \\
\hline Mills & 190 & 250 & 274 & 370 & $2.0 \%$ & $1.11\{0.76,1.61\}$ & 2002 & & & & \\
\hline Kakbo & 234 & 284 & 220 & 284 & $1.7 \%$ & $1.36[0.90,2.06]$ & 2002 & & & & \\
\hline Wamer & 159 & 178 & 169 & 184 & $0.7 \%$ & $0.74\{0.36,1.51\}$ & 2001 & & & & \\
\hline Gemmati & 393 & 480 & 359 & 480 & $2.6 \%$ & $1.52(1.12,2.08\}$ & 2001 & & & - & \\
\hline Franco & 242 & 300 & 215 & 300 & $2.0 \%$ & $1.65[1.13,2.41]$ & 2000 & & & & \\
\hline Canamy & 380 & 488 & 357 & 488 & $2.9 \%$ & $1.29[0.96,1.73\}$ & 2000 & & & & \\
\hline Corral & 168 & 202 & 167 & 202 & $1.2 \%$ & $1.04\{0.62,1.74\}$ & 2000 & & & & \\
\hline Kohler & 426 & 550 & 285 & 392 & $2.8 \%$ & $1.29[0.96,1.74]$ & 1999 & & & & \\
\hline Wartiovaara & 210 & 252 & 518 & 688 & $2.0 \%$ & $1.64[1.13,2.38]$ & 1999 & & & & \\
\hline Total $(95 \% \mathrm{Cl})$ & & 26940 & & 34694 & $100.0 \mathrm{~s}$ & $1.09[1.03,1.16]$ & & & & $\bullet$ & \\
\hline Total events & 20928 & & 26330 & & & & & & & & \\
\hline $\begin{array}{l}\text { Heterogeneis. Tau": } \\
\text { Test for overall effect }\end{array}$ & $\begin{array}{l}0.01 ; C^{2}=62 \\
Z=287(P=0\end{array}$ & $f=35(P$ & $=0.003)$ & $P=44 x$ & & & & 0.5 & ${ }^{0.7}{ }_{C A D}^{1}$ & ${ }_{\text {control }}^{1.5}$ & 2 \\
\hline
\end{tabular}

Figure 1. Odds ratio and $95 \%$ confidence interval $(\mathrm{Cl})$ of individual studies and pooled data for the association between the factor XIII Val allele and coronary artery disease (CAD).

polymorphism and CAD risk, including 26,940 cases and 34,694 controls. We found that the Val allele and Val/Val genotype showed increased risk of CAD. However, our meta-analyses did not show evidence of an association between factor XIII Val34Leu polymorphism and CAD in any subgroup except MI. These results are in accord with previous meta-analyses [5-7]. However, Wang et al. [6] suggested that factor XIII Val34Leu polymorphism was significantly associated with MI risk in the subgroup analyses by age and sex.

In the subgroup analysis by disease, the present meta-analysis showed that factor XIII Val34Leu polymorphism affected MI risk, but did not affect risk in $\mathrm{CAD}$ without $\mathrm{MI}$, although the $\mathrm{CAD}$ without MI group was small (9 studies). CAD involves damage from plaque accumulating on the arterial wall. The buildup of plaque progressively hardens and narrows blood vessels, a pro- cess known as atherosclerosis [45]. MI, a severe complication of CAD, is commonly defined as a cardiomyocyte death due to a prolonged ischemia and increase in serum cardiac markers, such as troponin [46]. Both $\mathrm{MI}$ and $\mathrm{CAD}$ without MI are caused by atherosclerosis, but MI differs from CAD without MI in the existence of cardiac necrosis. We suspect that factor XIII has a function not only in blood coagulation, but also in healing of tissue damage.

Blood coagulation factor XIII has a key role in the terminal phase of the clotting cascade, which contributes to thrombotic events. Factor XII is composed of A and B subunits. Factor XIII is activated by thrombin proteolytically and, in the presence of calcium, dissociation of subunit B [47]. Activated factor XIII induces fibrin cross-linking via noncovalent binding of fibrin polymers. This process finally forms a stable clot that is resistant 


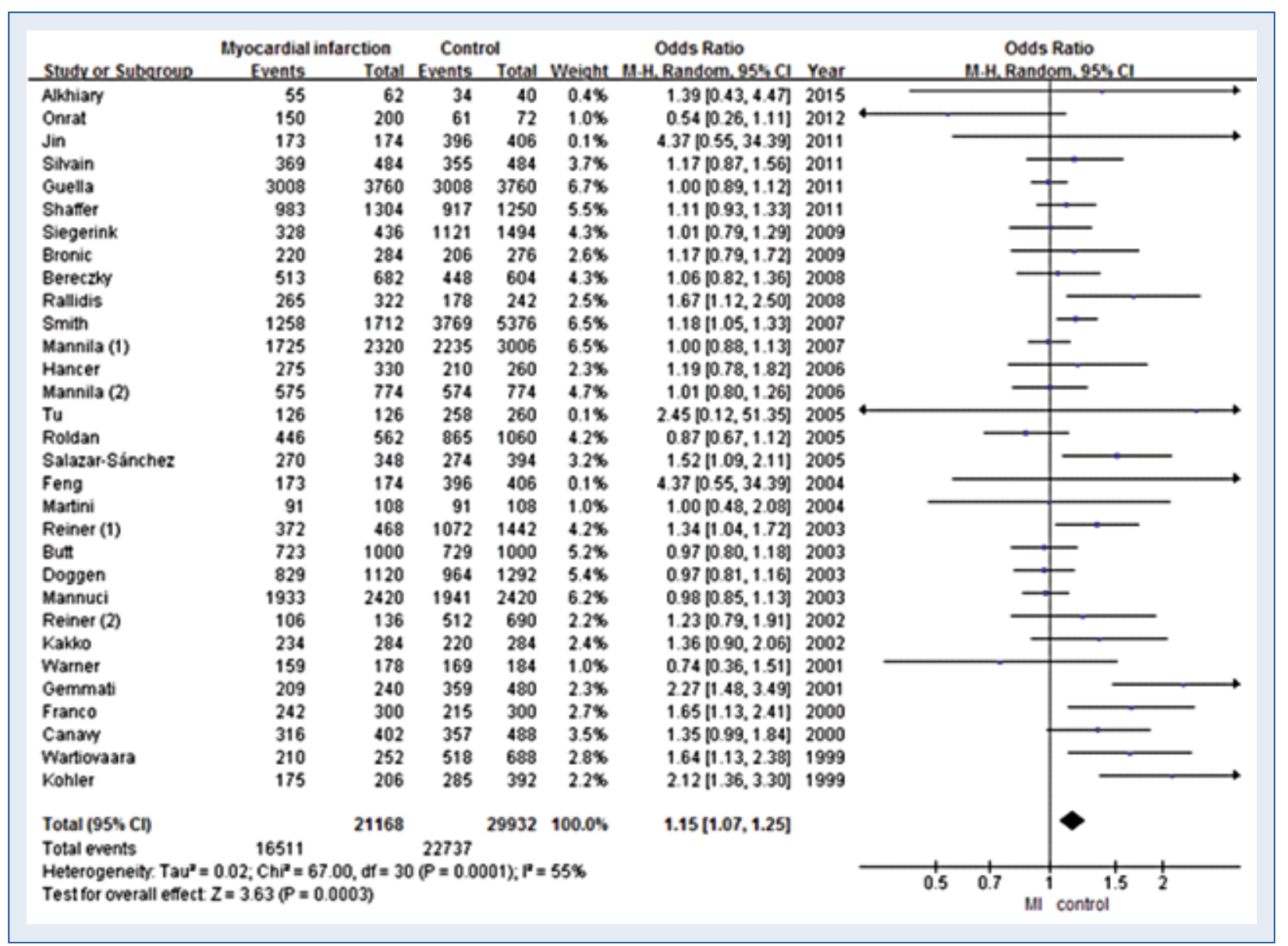

Figure 2. Odds ratio and $95 \%$ confidence interval $(\mathrm{Cl})$ of individual studies and data pooled for the association between the factor XIII Val allele and myocardial infarction (MI).

to shear forces and fibrinolysis [48]. The Val34Leu polymorphism in factor XIII A subunit is located in the activation peptide 3 amino acid residues upstream from the thrombin cleavage site [14]. The 34Leu variant increases activation rate by thrombin, alters fibrin structure in vitro, and influences fibrin cross-linking in vivo [47]. Compared to $\mathrm{CAD}$ without $\mathrm{MI}$, a vulnerable plaque is a cruel character of MI. Thus, MI can be protected against by increases in factor XIII due to the 34Leu variant. However, it remains unclear whether the 34Leu variant protects against CAD without MI. The present meta-analysis also showed no association between CAD without MI and factor XIII Val34Leu polymorphisms.

In subgroup analyses by age or sex, there were no associations between CAD and factor XIII Val34Leu polymorphisms. It is possible that the influence of factor XIII Val34Leu polymorphism on CAD might be confounded by the presence of other unidentified causal genes involved in CAD development. Gene-gene interactions should be considered. Fibrinogen is an independent predictor of atherosclerotic disease including MI [49]. The factor XIII A $34 \mathrm{Val}$ allele is associated with an increase in fibrinogen concentrations, as is the fibrinogen $\mathrm{A} \alpha$ 312Ala allele. Fibrinogen $\mathrm{A} \alpha \mathrm{Thr} 312 \mathrm{Ala}$ polymorphism is also associated with fibrinogen concentration. High fibrinogen concentrations lead to formation of a fibrin clot, which is highly thrombogenic [50]. In addition, factor XIII B His95Arg polymorphism is associated with development of MI when inherited with factor XIII A Val34Leu polymorphism. The Arg95 allele reduces MI risk in the presence of the Leu34 allele [33]. Factor II 20210A and factor V leiden variants are also associated with MI risk, and Tyr2047Phe and Pro564Leu variants in the factor XIII A gene are associated atherosclerotic disease $[18,30]$. Gene-environment interaction should also be considered. Fibrinogen concentrations are 


\begin{tabular}{|c|c|c|c|c|c|c|c|c|c|c|c|}
\hline \multirow[b]{2}{*}{ Studror Suberous } & \multicolumn{2}{|c|}{ Coronary artery disease } & \multicolumn{2}{|c|}{ Control } & \multirow{2}{*}{\multicolumn{3}{|c|}{$\begin{array}{l}\text { Odds Ratio } \\
\text { Weight } \text { M.H.Random.95s CI Year }\end{array}$}} & \multirow{2}{*}{\multicolumn{4}{|c|}{$\begin{array}{c}\text { Odds Ratio } \\
\text { M. H. Random, 95: CI }\end{array}$}} \\
\hline & Events & Total & Events & Total & & & & & & & \\
\hline Alkhiary & 45 & 52 & 15 & 20 & $0.3 \%$ & $2.14[0.59,7.77]$ & 2015 & & & & \\
\hline Güler & 27 & 48 & 29 & 36 & $0.5 \%$ & $0.31[0.11,0.85]$ & 2014 & & & & \\
\hline Onrat & 50 & 100 & 25 & 36 & $0.7 \%$ & $0.44[0.20,0.99]$ & 2012 & & & & \\
\hline Shaffer & 1203 & 1880 & 1203 & 1880 & $65 \%$ & $1.00[0.88,1.14]$ & 2011 & & & - & \\
\hline Silvain & 186 & 195 & 193 & 203 & $0.6 \%$ & $1.07[0.43,2.69]$ & 2011 & & & & \\
\hline Jin & 141 & 242 & 128 & 242 & $2.8 \%$ & $1.24[0.87,1.78$ & 2011 & & & & \\
\hline Guella & 370 & 652 & 336 & 625 & $4.7 \%$ & $1.13[0.90,1.41]$ & 2011 & & & - & \\
\hline Siegerink & 140 & 242 & 76 & 138 & $2.2 \%$ & $1.12[0.73,1.71]$ & 2009 & & & & \\
\hline Bronic & 124 & 218 & 419 & 747 & $3.4 \%$ & $1.03[0.76,1.40]$ & 2009 & & & - & \\
\hline Rallidis & 536 & 960 & 167 & 302 & $4.1 \%$ & $1.02[0.79,1.33]$ & 2008 & & & - & \\
\hline Bereczby & 111 & 161 & 64 & 121 & $1.8 \%$ & $1.98[1.21,3.22]$ & 2008 & & & & \\
\hline Mannila (1) & 641 & 1160 & 838 & 1503 & $6.1 \%$ & $0.98[0.84,1.14]$ & 2007 & & & - & \\
\hline Smath & 438 & 856 & 1321 & 2688 & $6.1 \%$ & $1.08[0.93,1.26]$ & 2007 & & & - & \\
\hline Mannila (2) & 458 & 898 & 868 & 1580 & $5.9 \%$ & $0.85[0.72,1.01]$ & 2006 & & & & \\
\hline Boekholdt & 120 & 165 & 82 & 130 & $1.7 \%$ & $1.56[0.95,2.56]$ & 2006 & & & 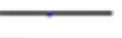 & \\
\hline Hancer & 209 & 387 & 213 & 387 & $3.7 \%$ & $0.96[0.72,1.27]$ & 2006 & & - & - & \\
\hline Tu & 63 & 63 & 128 & 130 & $0.1 \%$ & $2.47[0.12,52.24]$ & 2005 & & & & \\
\hline Roldan & 104 & 174 & 101 & 197 & $2.3 \%$ & $1.41[0.94 .2 .13]$ & 2005 & & & & \\
\hline Salazar-Sánchez & 180 & 281 & 354 & 530 & $3.4 \%$ & $0.89[0.65,1.20]$ & 2005 & & & - & \\
\hline Martini & 186 & 195 & 193 & 203 & $0.6 \%$ & $1.07[0.43,2.69]$ & 2004 & & & & \\
\hline Feng & 39 & 54 & 789 & 1210 & $1.2 \%$ & $1.39[0.76 .2 .55]$ & 2004 & & & & \\
\hline Reiner (1) & 265 & $\mathbf{5 0 0}$ & 261 & 500 & $4.2 \%$ & $1.03[0.81,1.32]$ & 2003 & & & 一 & \\
\hline Mannuci & 313 & 560 & 358 & 646 & $4.6 \%$ & $1.02[0.81,1.28]$ & 2003 & & & - & \\
\hline Doggen & 779 & 1210 & 789 & 1210 & $5.8 \%$ & $0.96[0.82,1.14]$ & 2003 & & & - & \\
\hline Buat & 152 & 234 & 406 & 721 & $3.4 \%$ & $1.44[1.06,1.95]$ & 2003 & & & & \\
\hline Aleksic & 41 & 68 & 187 & 345 & $1.5 \%$ & $1.28[0.76 .2 .18]$ & 2002 & & & & \\
\hline Kakko & 256 & 423 & 295 & 479 & $3.9 \%$ & $0.96[0.73,1.25]$ & 2002 & & & - & \\
\hline Mills & 98 & 142 & 88 & 142 & $1.7 \%$ & $1.37[0.84,2.23]$ & 2002 & & & & \\
\hline Reiner (2) & 75 & 125 & 104 & 185 & $1.9 \%$ & $1.17[0.74,1.85]$ & 2002 & & & & \\
\hline Warner & 165 & 240 & 136 & 240 & $26 \%$ & $1.68[1.16,2.44]$ & 2001 & & & & \\
\hline Gemmat & 73 & 89 & 78 & 92 & $0.8 \%$ & $0.82[0.37,1.80]$ & 2001 & & & & \\
\hline Franco & 148 & 244 & 129 & 244 & $28 \%$ & $1.37[0.96,1.97]$ & 2000 & & & & \\
\hline Canawy & 96 & 150 & 77 & 150 & $1.9 \%$ & $1.69[1,06.2 .68]$ & 2000 & & & & \\
\hline Corral & 68 & 101 & 68 & 101 & $1.3 \%$ & $1.00[0.56,1.80]$ & 2000 & & & & \\
\hline Kohler & 164 & 275 & 102 & 196 & $2.7 \%$ & $1.36[0.94,1.97]$ & 1999 & & & & \\
\hline Wartiovaara & 87 & 126 & 195 & 344 & 2.18 & $1.70[1.10,2.63]$ & 1999 & & & & \\
\hline Total $(95 \% \mathrm{Cl})$ & & 13470 & & 18503 & $100.0 \%$ & $1.11[1.03,1.19]$ & & & & $\bullet$ & \\
\hline Total events & 8151 & & 10815 & & & & & & & & \\
\hline $\begin{array}{l}\text { Heterogeneity. Tau" } \\
\text { Test for overall effect }\end{array}$ & $\begin{array}{l}0.02 ; \text { ChP }^{\prime}=60 . \\
Z=2.73(P=0.0\end{array}$ & $=35(\mathrm{P}:$ & $=0.005)$. & $P=42 \%$ & & & & 0.2 & ${ }^{0.5} \mathrm{CAO}^{1}$ & control $^{2}$ & 5 \\
\hline
\end{tabular}

Figure 3. Odds ratio and 95\% confidence interval $(\mathrm{Cl})$ of individual studies and data pooled for the association between the factor XIII Val/Val genotype and coronary artery disease (CAD).

associated with smoking, insulin resistance and physical activity [50]. The 34Leu allele is related to taking estrogen [48].

In recent years, another aspect of factor XIII has been identified in addition to blood coagulation. Factor XIII influences wound healing in several tissues, including cardiomyocytes, by exerting multiple plasma and cellular functions. Moreover, the proangiogenic function of factor XIII is directed by the interaction of vascular endothelial growth factor receptor 2 and integrin $\alpha \mathrm{V} \beta_{3}$ on the cell membrane [51]. Certain studies showed that low factor XIIIA level correlated with a poor prognosis with regard to MI $[52,53]$. Therefore, MI could be differently affected by this function of factor XIII compared to CAD without MI.

The present meta-analysis has several strengths. It included the largest number of studies. Previous meta-analyses included primarily Caucasians, however this meta-analysis contained other ethnicities including Asians. In addition, we used real gene polymorphism data in the meta-analysis rather than adjusted ORs, which could reduce the bias arising from adjustment.

\section{Limitations of the study}

As with any meta-analysis, there are a number of limitations that need to be considered. First, the proportion of studies with MI was too large. Among 36 studies, MI was included in 31 studies, which could overestimate the association between gene polymorphism and overall CAD. Second, although we sought to study gene effects in all ethnic groups, the majority of studies were conducted in Caucasian populations. Third, each study was not analyzed using uniform inclusion and exclusion criteria. Each 


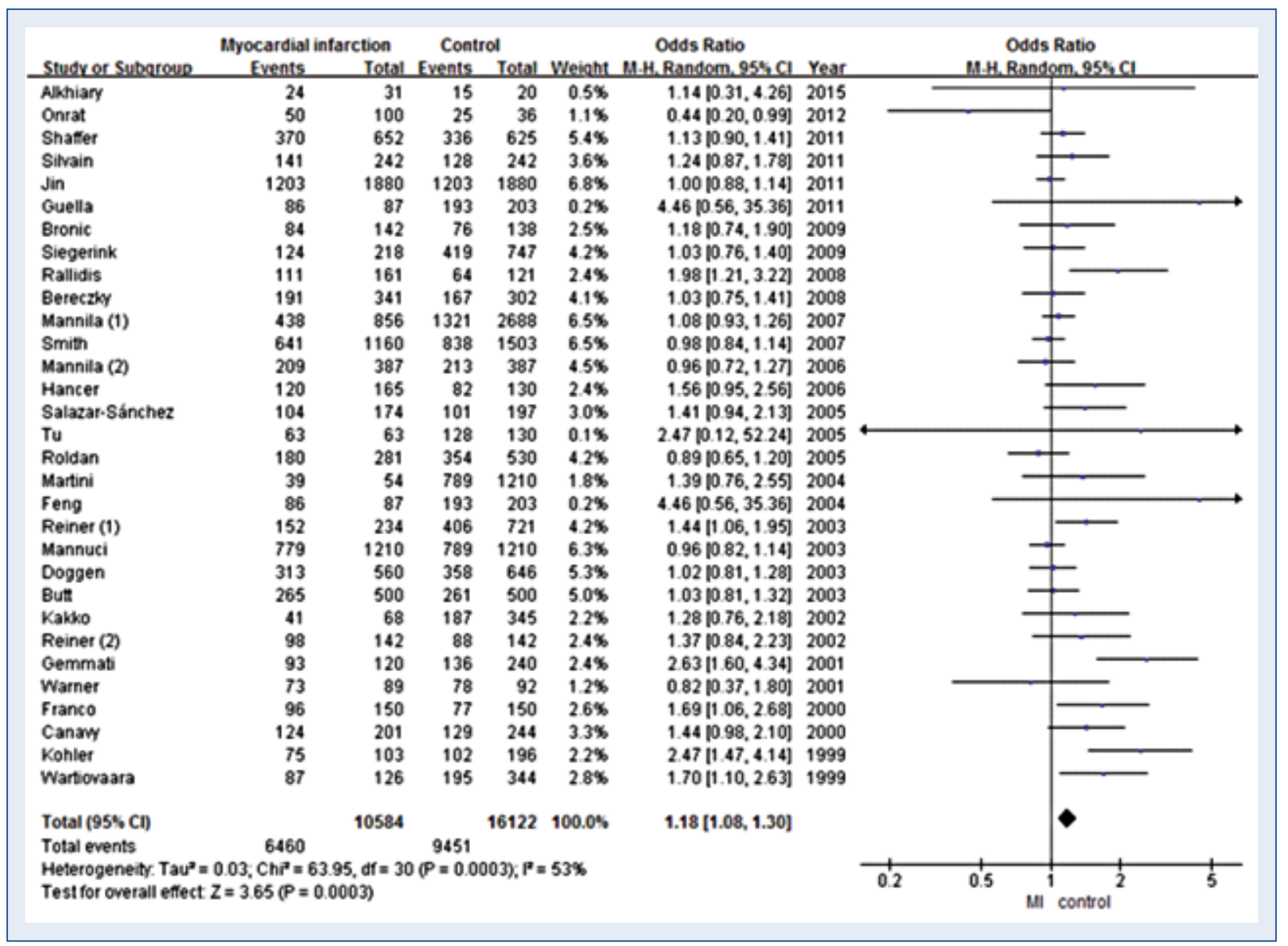

Figure 4. Odds ratio and $95 \%$ confidence interval (Cl) of individual studies and data pooled for the association between the factor XIII Val/Val genotype and myocardial infarction (MI).

Table 3. Meta-analysis of association between the factor XIII Val34Leu polymorphism and myocardial infarction.

\begin{tabular}{|c|c|c|c|c|c|c|}
\hline & \multicolumn{3}{|c|}{ Test of association } & \multicolumn{3}{|c|}{ Test of heterogeneity } \\
\hline & OR & $95 \% \mathrm{Cl}$ & $\mathbf{P}$ & Model & $\mathbf{P}$ & $I^{2}(\%)$ \\
\hline V vs. L & 1.15 & $1.07-1.25$ & 0.0003 & $\mathrm{R}$ & 0.0001 & 55 \\
\hline VV vs. VL+LL & 1.18 & $1.08-1.30$ & 0.0003 & $\mathrm{R}$ & 0.0003 & 53 \\
\hline$V V+V L$ vs. LL & 1.21 & $1.02-1.43$ & 0.003 & $\mathrm{R}$ & 0.02 & 39 \\
\hline VV vs. LL & 1.27 & $1.06-1.52$ & 0.009 & $\mathrm{R}$ & 0.009 & 44 \\
\hline
\end{tabular}

$\mathrm{Cl}$ - confidence interval; $\mathrm{L}$ - factor XIII Leu; OR — odds ratio; $\mathrm{R}$ - random effects model; $\mathrm{V}$ - factor XIII Val

study also differently defines MI, even though each definition of MI was mostly based on ischemic symptom, change of electrocardiography, and elevation of cardiac biomarkers. Fourth, in addition to Val34Leu polymorphism, the factor XIII A gene includes other genetic variants, such as tyr204Phe and Pro564Leu [18]. Fifth, due to the lack of the original data of the eligible studies, the evaluation of the effects of gene-gene or gene-environment interactions was limited, as well as the ability to perform subgroup analyses by age and sex. Sixth, all included studies were retrospective case-control studies, thus, we cannot exclude the possibility of undetected bias. Finally, publication bias is an important feature of meta-analyses, which we attempted to minimize by including studies in all languages. 


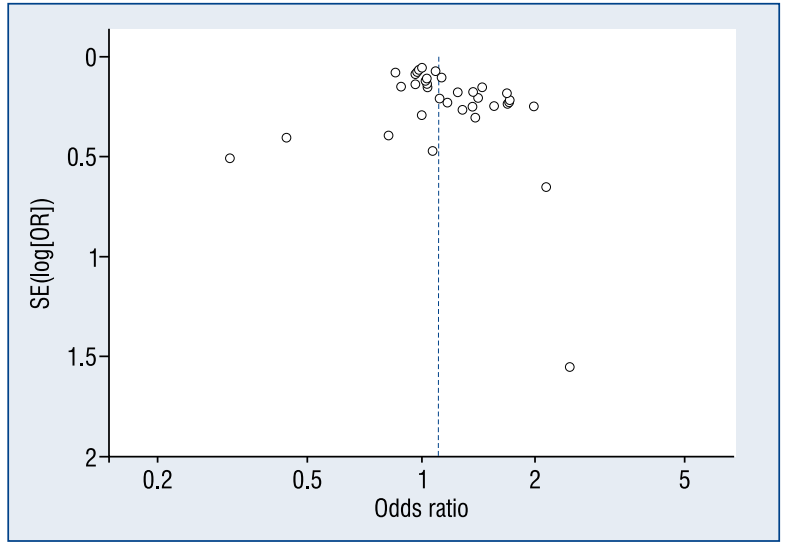

Figure 5. Funnel plot for coronary artery disease risk and factor XIII Val34Leu polymorphism.

\section{Conclusions}

In conclusion, this meta-analysis showed that factor XIII Val34Leu polymorphism was associated with CAD risk, especially with MI, but not with CAD without MI. In addition, age or sex did not affect the relationship between factor XIII Val34Leu polymorphism and CAD risk. However, some significant limitations exist in the interpretation of the result and the present meta-analysis should be interpreted with caution.

\section{Acknowledgements}

This study was supported by Korea University Medical College grant.

\section{Conflict of interest: None declared}

\section{References}

1. Mozaffarian D, Benjamin EJ, Go AS et al. Heart Disease and Stroke Statistics, 2016 Update: A Report From the American Heart Association. Circulation, 2016; 133: e38-e60. doi: 10.1161/ CIR.0000000000000350.

2. Bereczky Z, Balogh E, Katona E et al. Decreased factor XIII levels in factor XIII A subunit Leu34 homozygous patients with coronary artery disease. Thromb Res, 2008; 121: 469-476. doi: 10.1016/j.thromres.2007.05.012.

3. Sharief LA, Lawrie AS, Mackie IJ et al. Plasma factor XIII level variations during menstrual cycle. Blood Coagul Fibrinolysis, 2016. doi: 10.1097/MBC.0000000000000491 2007.05.012.

4. Muszbek L, Bereczky Z, Bagoly Z, Shemirani AH, Katona E. Factor XIII and atherothrombotic diseases. Semin Thromb Hemost, 2010; 36: 18-33. doi: 10.1055/s-0030-1248721.

5. Chen F, Qiao Q, Xu P, Fan B, Chen Z. Effect of factor XIII-A Val34Leu polymorphism on myocardial infarction risk: A metaanalysis. Clin Appl Thromb Hemost, 2014; 20: 783-792. doi: $10.1177 / 1076029613504130$.
6. Wang G, Zou Z, Ji X, Ni Q, Ma Z. Factor XIII-A Val34Leu polymorphism might beassociated with myocardial infarction risk: An updated meta-analysis. Int J Clin Exp Med, 2014; 7: 5547-5552.

7. Voko Z, Bereczky Z, Katona E, Adany R, Muszbek L. Factor XIII Val34Leu variant protects against coronary artery disease. A meta-analysis. Thromb Haemost, 2007; 97: 458-463.

8. Higgins JP, Thompson SG. Quantifying heterogeneity in a metaanalysis. Stat Med, 2002; 21: 1539-1558. doi: 10.1002/sim.1186.

9. Thakkinstian A, McElduff P, D'Este C, Duffy D, Attia J. A method for meta-analysis of molecular association studies. Stat Med, 2005; 24: 1291-1306. doi: 10.1002/sim.2010.

10. Alkhiary W, Azzam H, Yossof MM, Aref S, Othman M, ElSharawy S. Association of hemostatica gene polymorphisms with early-onset ischemic heart disease in Egyptian patients. Clin Appl Thromb Hemost, 2016; 22: 535-542. doi: 10.1177/1076029615572466.

11. Guler GB, Batgerel U, Guler E et al. Factor XIII Val34Leu polymorphism in patients with cardiac syndrome X. Cardiol J, 2014; 21: 6-10. doi: 10.5603/CJ.a2013.0046.

12. Onrat ST, Akci O, Soylemez Z, Onrat E, Avsar A. Prevalence of myocardial infarction polymorphisms in Afyonkarahisar, Western Turkey. Mol Biol Rep, 2012; 39: 9257-9264. doi: 10.1007/s11033-012-1799-1.

13. Guella I, Duga S, Ardissino D et al. Common variants in the haemostatic gene pathway contribute to risk of early-onset myocardial infarction in the Italian population. Thromb Haemost, 2011; 106: 655-664. doi: 10.1160/TH11-04-0247.

14. Guodong J, Beili F, Peng C et al. Coagulation factor XIII-A Val34Leu polymorphism and the risk of coronary artery disease and myocardial infarction in a Chinese Han population. Clin Appl Thromb Hemost, 2011; 17: 208-213. doi: 10.1177/1076029609355152.

15. Shaffer JR, Kammerer CM, Dorn J et al. Polymorphisms in the platelet-specific collagen receptor GP6 are associated with risk of nonfatal myocardial infarction in Caucasians. Nutr Metab Cardiovasc Dis, 2011; 21: 546-552. doi: 10.1016/j.numecd.2009.12.002.

16. Silvain J, Pena A, Vignalou JB et al. FXIII-A Leu34 genetic variant in premature coronary artery disease: A genotype-phenotype case control study. Thromb Haemost, 2011; 106: 511-520. doi: 10.1160/TH11-01-0027.

17. Bronic A, Ferencak G, Zadro R, Stavljenic-Rukavina A, Bernat R. Impact of FXIII-A Val34Leu polymorphism on coronary artery disease in Croatian patients. Mol Biol Rep, 2009; 36: 1-5. doi: 10.1007/s11033-007-9144-9.

18. Siegerink B, Algra A, Rosendaal FR. Genetic variants of coagulation factor XIII and the risk of myocardial infarction in young women. Br J Haematol, 2009; 146: 459-461. doi: 10.1111/j.13652141.2009.07805.x.

19. Rallidis LS, Politou M, Komporozos C et al. Factor XIII Val34Leu polymorphism and the risk of myocardial infarction under the age of 36 years. Thromb Haemost, 2008; 99: 1085-1089. doi: 10.1160/TH07-12-0755.

20. Mannila MN, Eriksson P, Leander K et al. The association between fibrinogen haplotypes and myocardial infarction in men is partly mediated through pleiotropic effects on the serum IL-6 concentration. J Intern Med, 2007; 261: 138-147. doi: 10.1111/j.1365-2796.2006.01749.x.

21. Smith NL, Bis JC, Biagiotti S et al. Variation in 24 hemostatic genes and associations with non-fatal myocardial infarction and ischemic stroke. J Thromb Haemost, 2008; 6: 45-53. doi: 10.1111/j.1538-7836.2007.02795.x. 
22. Boekholdt SM, Sandhu MS, Wareham NJ, Luben R, Reitsma PH, Khaw KT. Fibrinogen plasma levels modify the association between the factor XIII Val34Leu variant and risk of coronary artery disease: The EPIC-Norfolk prospective population study. J Thromb Haemost, 2006; 4: 2204-2209. doi: 10.1111/j.15387836.2006.02154.x.

23. Hancer VS, Diz-Kucukkaya R, Bilge AK et al. The association between factor XIII Val34Leu polymorphism and early myocardial infarction. Circ J, 2006; 70: 239-242.

24. Mannila MN, Eriksson P, Ericsson CG, Hamsten A, Silveira A. Epistatic and pleiotropic effects of polymorphisms in the fibrinogen and coagulation factor XIII genes on plasma fibrinogen concentration, fibrin gel structure and risk of myocardial infarction. Thromb Haemost, 2006; 95: 420-427. doi: 10.1160/TH05-11-0777.

25. Roldan V, Gonzalez-Conejero R, Marin F, Pineda J, Vicente V, Corral J. Five prothrombotic polymorphisms and the prevalence of premature myocardial infarction. Haematologica, 2005; 90: 421-423.

26. Salazar-Sanchez L, Chaves L, Cartin M et al. Common polymorphisms and cardiovascular factors in patients with myocardial infarction of Costa Rica. Rev Biol Trop, 2006; 54: 1-11.

27. Tu CQ, Wu JZ, Xie CY et al. Association between polymorphism of coagulation factor XIII Val34Leu and ischemic arterial thrombotic diseases in Han population. Chin J Clin Rehabil, 2005; 9: 70-71.

28. Feng BL, Xu G, Jin GD et al. The relationship between factor XIII Vasl34Leu variant and coronary artery disease. Chin J Pathophysiology, 2004; 20: 1823-1826.

29. Martini CH, Doggen CJ, Cavallini C, Rosendaal FR, Mannucci PM. No effect of polymorphisms in prothrombotic genes on the risk of myocardial infarction in young adults without cardiovascular risk factors. J Thromb Haemost, 2005; 3: 177-179. doi: 10.1111/j.1538-7836.2004.01080.x.

30. Butt C, Zheng H, Randell E, Robb D, Parfrey P, Xie YG. Combined carrier status of prothrombin 20210A and factor XIII-A Leu34 alleles as a strong risk factor for myocardial infarction: Evidence of a gene-gene interaction. Blood, 2003; 101: 30373041. doi: 10.1182/blood-2002-09-2888.

31. Doggen CJ, Reiner AP, Vos HL, Rosendaal FR. Two factor XIII gene polymorphisms associated with a structural and functional defect and the risk of myocardial infarction in men. J Thromb Haemost, 2003; 1: 2056-2058.

32. Atherosclerosis, Thrombosis, and Vascular Biology Italian Study Group. No evidence of association between prothrombotic gene polymorphisms and the development of acute myocardial infarction at a young age. Circulation, 2003; 107: 1117-1122.

33. Reiner AP, Heckbert SR, Vos HL et al. Genetic variants of coagulation factor XIII, postmenopausal estrogen therapy, and risk of nonfatal myocardial infarction. Blood, 2003; 102: 25-30. doi: 10.1182/blood-2002-07-2308.

34. Aleksic N, Ahn C, Wang YW et al. Factor XIIIA Val34Leu polymorphism does not predict risk of coronary heart disease: The Atherosclerosis Risk in Communities (ARIC) Study. Arterioscler Thromb Vasc Biol, 2002; 22: 348-352.

35. Kakko S, Elo T, Tapanainen JM, Huikuri HV, Savolainen MJ. Polymorphisms of genes affecting thrombosis and risk of myocardial infarction. Eur J Clin Invest, 2002; 32: 643-648.

36. Mills JD, Mansfield MW, Grant PJ. Factor XIII-circulating levels and the Val34Leu polymorphism in the healthy male relatives of patients with severe coronary artery disease. Thromb Haemost, 2002; 87: 409-414.
37. Reiner AP, Frank MB, Schwartz SM et al. Coagulation factor XIII polymorphisms and the risk of myocardial infarction and ischaemic stroke in young women. Br J Haematol, 2002; 116: 376-382.

38. Gemmati D, Serino ML, Ongaro A et al. A common mutation in the gene for coagulation factor XIII-A (VAL34Leu): A risk factor for primary intracerebral hemorrhage is protective against atherothrombotic diseases. Am J Hematol, 2001; 67: 183-188. doi: 10.1002/ajh.1104.

39. Warner D, Mansfield MW, Grant PJ. Coagulation factor XIII and cardiovascular disease in UK Asian patients undergoing coronary angiography. Thromb Haemost, 2001; 85: 408-411.

40. Canavy I, Henry M, Morange PE et al. Genetic polymorphisms and coronary artery disease in the south of France. Thromb Haemost, 2000; 83: 212-216.

41. Corral J, Gonzalez-Conejero R, Iniesta JA, Rivera J, Martinez C, Vicente V. The FXIII Val34Leu polymorphism in venous and arterial thromboembolism. Haematologica, 2000; 85: 293-297.

42. Franco RF, Pazin-Filho A, Tavella MH, Simoes MV, Marin-Neto JA, Zago MA. Factor XIII val34leu and the risk of myocardial infarction. Haematologica, 2000; 85: 67-71.

43. Kohler HP, Futers TS, Grant PJ. Prevalence of three common polymorphisms in the A-subunit gene of factor XIII in patients with coronary artery disease. Thromb Haemost, 1999; 81: 511-515.

44. Wartiovaara U, Perola M, Mikkola $\mathrm{H}$ et al. Association of FXIII Val34Leu with decreased risk of myocardial infarction in Finnish males. Atherosclerosis, 1999; 142: 295-300.

45. Molina E, Clarence EM, Ahmady F, Chew GS, Charchar FJ. Coronary artery disease: Why we should consider the $\mathrm{Y}$ chromosome. Heart Lung Circ, 2016; 25: 791-801. doi: 10.1016/j.hlc.2015.12.100.

46. Montecucco F, Carbone F, Schindler TH. Pathophysiology of ST-segment elevation myocardial infarction: Novel mechanisms and treatments. Eur Heart J, 2016; 37: 1268-1283. doi: 10.1093/ eurheartj/ehv592.

47. Duval C, Ali M, Chaudhry WW, Ridger VC, Ariens RA, Philippou H. Factor XIII A-Subunit V34L variant affects thrombus cross-linking in a murine model of thrombosis. Arterioscler Thromb Vasc Biol, 2016; 36: 308-316. doi: 10.1161/ATVBAHA.115.306.

48. Kobbervig C, Williams E. FXIII polymorphisms, fibrin clot structure and thrombotic risk. Biophys Chem, 2014; 112: 223-228. doi: 10.1016/j.bpc.2004.07.023.

49. Wilhelmsen L, Svardsudd K, Korsan-Bengtsen K, Larsson B, Welin L, Tibblin G. Fibrinogen as a risk factor for stroke and myocardial infarction. N Engl J Med, 1984; 311: 501-505. doi: 10.1056/NEJM198408233110804.

50. Lim BC, Ariens RA, Carter AM, Weisel JW, Grant PJ. Genetic regulation of fibrin structure and function: Complex gene-environment interactions may modulate vascular risk. Lancet, 2013; 361: 1424-1431. doi: 10.1016/S0140-6736(03)13135-2.

51. Gemmati D, Vigliano M, Burini F et al. Coagulation Factor XIIIA (F13A1): Novel Perspectives in Treatment and Pharmacogenetics. Curr Pharm Des, 2016; 22: 1449-1459.

52. Gemmati D, Zeri G, Orioli E et al. Factor XIII-A dynamics in acute myocardial infarction: A novel prognostic biomarker? Thromb Haemost, 2015; 114: 123-132. doi: 10.1160/TH14-11-0952.

53. Gemmati D, Federici F, Campo G et al. Factor XIIIA-V34L and factor XIIIB-H95R gene variants: Effects on survival in myocardial infarction patients. Mol Med, 2007; 13: 112-120. doi: 10.2119/2006-00049.Gemmati. 